\title{
CORRIGENDUM
}

\section{Movement analyses of wood cricket (Nemobius sylvestris) (Orthoptera: Gryllidae) - CORRIGENDUM}

\author{
N.C. Brouwers and A.C. Newton \\ doi:10.1017/S0007485309990332, by Cambridge University Press, 11 December 2009.
}

The authors apologise for the error in the Equation $1 \mathrm{~b}$, on page 5 of their paper.

The Equation should read as follows:

$R_{n}^{2}=n L_{2}+\left(2 L_{1}^{2}\right)(c /(1-c))\left(n-\left(1-c^{n}\right) /(1-c)\right)$

\section{Reference}

Brouwers, N.C. \& Newton, A.C. (2009). Movement analyses of wood cricket (Nemobius sylvestris) (Orthoptera: Gryllidae). Bulletin of Entomological Research, Published by Cambridge University Press, 11 December 2009. doi:10.1017/S0007485309990332. 